\title{
Development and Testing of the Orion CEV Parachute Assembly System (CPAS)
}

\author{
David Lichodziejewski ${ }^{1}$, Anthony P. Taylor ${ }^{2}$, Robert Sinclair ${ }^{3}$, Randy Olmstead ${ }^{4}$ \\ Christopher Kelley ${ }^{5}$, Justin Johnson ${ }^{6}$ \\ Airborne System, Santa Ana, CA, 92704 \\ Michael Melgares ${ }^{7}$, Aaron Morris ${ }^{8}$, Kristin Bledsoe ${ }^{9}$ \\ Jacobs Engineering, Houston , TX 77058
}

\begin{abstract}
$\underline{\text { Abstract }}$
The Crew Exploration Vehicle (CEV) is an element of the Constellation Program that includes launch vehicles, spacecraft, and ground systems needed to embark on a robust space exploration program. As an anchoring capability of the Constellation Program, the CEV shall be human-rated and will carry human crews and cargo from Earth into space and back again. Coupled with transfer stages, landing vehicles, and surface exploration systems, the CEV will serve as an essential component of the architecture that supports human voyages to the Moon and beyond. In addition, the CEV will be modified, as required, to support International Space Station (ISS) mission requirements for crewed and pressurized cargo configurations.

Headed by Johnson Space Center (JSC), NASA selected Jacobs Engineering as the support contractor to manage the overall CEV Parachute Assembly System (CPAS) program development. Airborne Systems was chosen to develop the parachute system components. General Dynamics Ordnance and Tactical Systems (GD-OTS) was subcontracted to Airborne Systems to provide the mortar systems. Thus the CPAS development team of JSC, Jacobs, Airborne Systems and GD-OTS was formed.

The CPAS team has completed the first phase, or Generation I, of the design, fabrication, and test plan. This paper presents an overview of the CPAS program including system requirements and the development of the second phase, known as the Engineering Development Unit (EDU) architecture. We also present top level results of the tests completed to date. A significant number of ground and flight tests have been completed since the last CPAS presentation at the 2007 AIAA ADS Conference.
\end{abstract}

\section{Nomenclature}

$C P A S=$ Crew Exploration Vehicle (CEV) Parachute Assembly System

$C M S=$ Cradle Monorail System

$D D T=$ Drogue Development Test

$D G P S=$ Differential GPS (Global Positioning System)

$D T V=$ Drop Test Vehicle

$E F T C=$ Extraction Force Transfer Coupling

$L V A D=$ Low Velocity Air Drop

$M-D T V=$ Medium Drop Test Vehicle

\footnotetext{
${ }^{1}$ Program Manager, Space and Recovery, 3000 West Segerstrom Ave., CA 92704, AIAA Member

2 Technical Director, Space Market, 3000 West Segerstrom Ave., CA 92704, AIAA Member

${ }^{3}$ Chief Engineer, Space and Recovery, 3000 West Segerstrom Ave., CA 92704, AIAA Member

${ }^{4}$ Systems Analyst, Engineering Services, 3000 Segerstrom Ave, Santa Ana, CA 92704, Professional Member

${ }^{5}$ Design Lead, Engineering Services, 3000 Segerstrom Ave, Santa Ana, CA 92704, AIAA Member

${ }^{6}$ Operations Lead, Space and Recovery Group, 2224 Bay Area Blvd, Houston, TX 77058, AIAA Member

${ }^{7}$ Program Manager, CPAS Analysis Group, 2224 Bay Area Blvd, Houston, TX 77058, AIAA Member

${ }^{8}$ Operation Manager, CPAS Analysis Group, 2224 Bay Area Blvd, Houston, TX 77058, AIAA Member

${ }^{9}$ Aerospace Engineer, CPAS Analysis Group, 2224 Bay Area Blvd, Houston, TX 77058, Non-member
} 
$P D T=$ Pilot Development Test

$Y P G=$ Yuma Proving Ground

$V P C R=$ Variable Porosity Conical Ribbon

\section{Introduction}

In 2004, President Bush articulated his "Vision for Space Exploration." The nation wanted its space program to go to the Moon, support ISS, and journey to Mars. A new spacecraft, specifically designed for these missions, was required. The higher velocities of Lunar and interplanetary trajectories make Earth re-entry with a winged vehicle problematic at best, impossible at worst. A capsule shape was proven effective for Lunar missions during the Apollo program. Thus, for the next US crewed spacecraft, NASA has chosen a capsule shape similar to the Apollo vehicle, but larger and significantly more capable.

Additionally, a crew escape capability is required of this new spacecraft. Full capsule escape and recovery was selected, similar to the Apollo approach. Many studies have shown that once parachutes are onboard the spacecraft for the crew escape function, these same parachutes quickly become the primary landing system due to the mass efficiencies of this approach. Orion will use the parachute system for crew escape and primary landing. That parachute system is called the CEV Parachute Assembly System (CPAS). The status of development of the CPAS system is described below.

\section{$\underline{\text { II. Engineering Development Unit (EDU) }}$}

\section{A. Engineering Development Unit Requirements}

The Flight Design Unit requirements for a human crewed system are many. Only a few of the highlights are mentioned here. The CEV Crew Module will weigh 20,865 lbs and the maximum sink rate at touchdown will be no greater than $33 \mathrm{ft} / \mathrm{s}$ under two main parachutes (one main parachute failed condition) in a 3-sigma dispersed atmosphere at White Sands Missile Range. At no point during the deployment and descent can the CPAS system impart more than $5 \mathrm{G}$ to the Crew Module. The system will be designed to withstand a skipped reefing stage on either the drogues or mains, and to provide nominal reentry with a main and/or drogue parachute failed. Further, the system must provide a safe descent under both Pad Abort and Ascent Abort conditions. The CPAS system must weigh less than 1,124 lbs. The system must withstand the acceleration, vibration, shock, and pressure and other environs during the mission and still deploy nominally.

\section{B. Engineering Development Unit System Architecture}

During the development and testing of the Generation I system ${ }^{(1)}$, the flight dynamics team at Lockheed and JSC were studying the performance of the LAS and the entry aerodynamics. These studies concluded that the singlepoint off-CG drogue attachment, combined with the vehicle aerodynamics, would result in a condition that placed the capsule in an apex forward condition at main parachute line stretch. This drove the team to conclude that the main parachute risers would come into contact with hot structure during the inflation and high load events. A solution to this problem was essential.

Further study demonstrated that a drogue attachment architecture that straddled the CG of the vehicle would damp the capsule oscillations to a point that would eliminate the apex forward occurrences. This architecture could be accomplished by one of two methods:

- Attach the drogues to the Forward Bay Cover (FBC) and stabilize the capsule prior to FBC release.

- Jettison the $\mathrm{FBC}$ and attach the drogues to the gussets on the forward bay.

The results of a detailed study determined that the rigging and deployment complications introduced by the latter would degrade reliability to a point to where the benefits were negated; these were magnified by the fault tolerance requirements. The former FBC attachment introduced unique problems that were considered solvable.

The major problems with deploying the main parachutes during the $\mathrm{FBC}$ release are:

- Protection of the main parachute packs from contact with the hot FBC inner mold line.

- Snatch loads resulting from the separation velocity between the FBC and main bag extraction.

- Near and far field re-contact of the FBC with the terminal descent parachute system.

Extensive studies were conducted to establish the thermal and mechanical loads generated by various deployment schemes. Four different architectures were competed to determine an optimal solution:

- Rigid Attach - A rigid box, attached to the FBC, from which the main parachute deployed directly. 
- Loosely Coupled - An extended main deployment bag handle which allows the FBC to clear the top of the capsule prior to main deployment bag pick up.

- Closely Coupled - A close attachment, which limits the delta velocity between the FBC and main parachute packs and thus reduces inertial loads.

- Pilot Parachute Deployment - Employ the drogues and FBC to act as a deployment device to deploy a suite of individual pilot parachutes to deploy the main parachutes.

The primary discriminators in this architecture trade study were system reliability and system mass.

The results of this extensive and detailed study are worthy of a paper in their own right, but are beyond the scope of this paper. The results of this study enabled the team to converge on the architecture described below. This architecture, Figure 1, is described as follows:

- Drogues are mortar deployed

- Drogues inflate to first stage reefing ratio

- Drogues disreef to second stage

- Drogues disreef to full open

- Forward Bay Cover and drogues are jettisoned

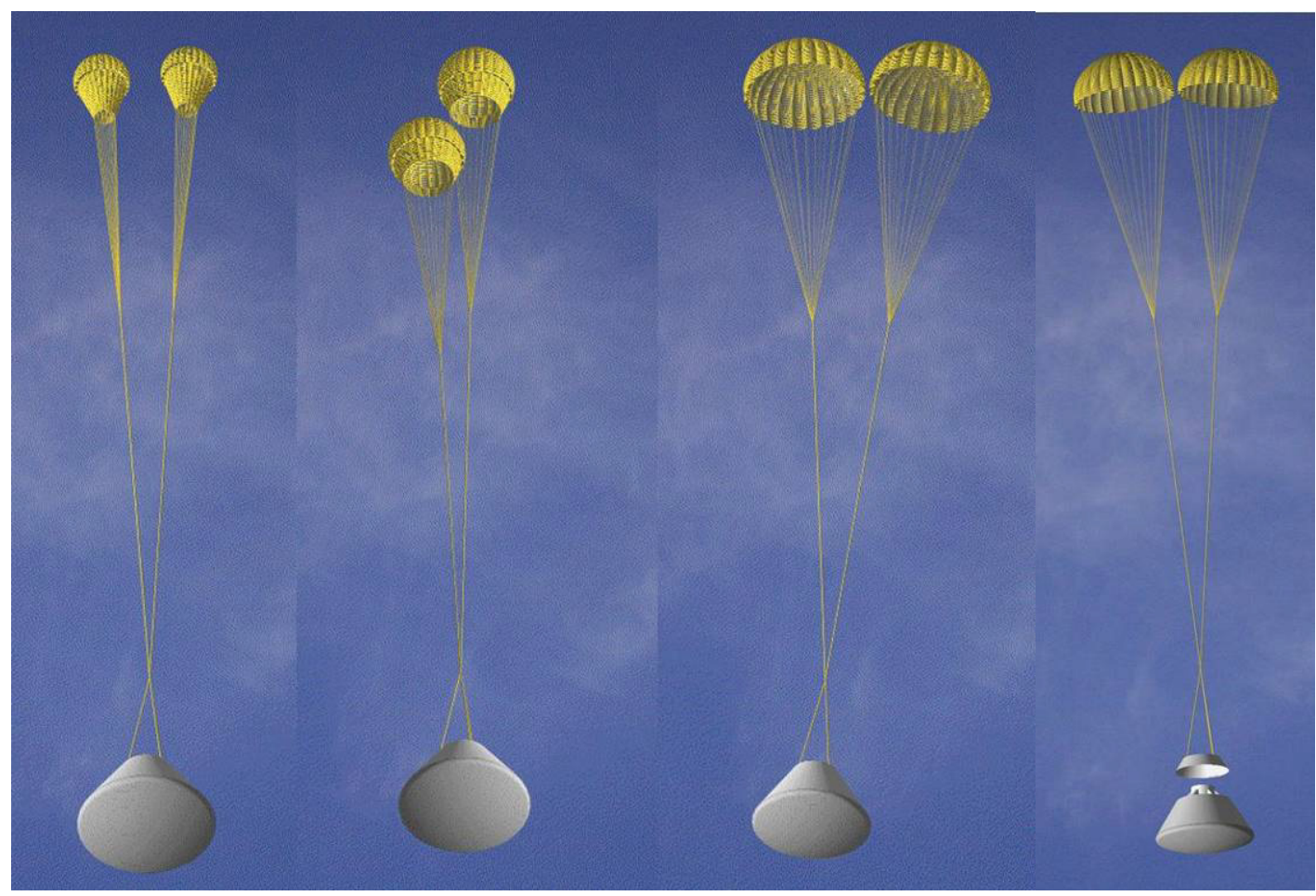

Figure 1. Drogue Deployment Sequence (Airborne Systems)

The FBC structure required a two-stage reefing schedule on the drogue parachutes for loads management, including the skipped reefing requirements. Figure 1 shows the drogue deployment sequence for a nominal entry. Following the drogue stage the $\mathrm{FBC}$ is released and the mains are deployed by pilot parachutes as described below.

The FBC is released and the pilot parachutes are deployed via static line by the FBC and remove the main parachute packs from the capsule, Figure 2. The main parachutes deploy and stage through two stages of reefing. The capsule is oriented at the required 28 degree hang angle. 


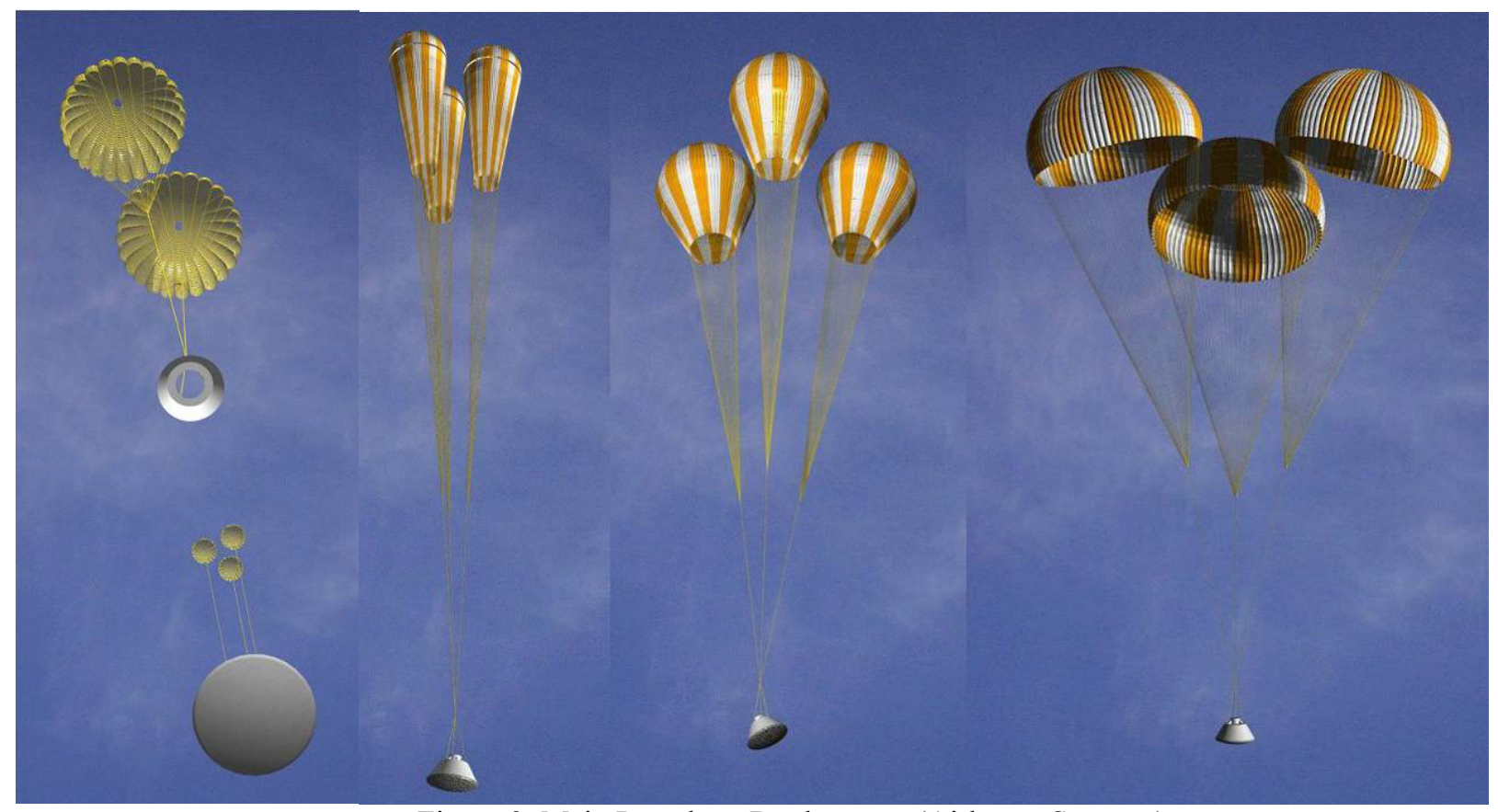

Figure 2. Main Parachute Deployment (Airborne Systems)

\section{Pad Abort}

Pad abort provides unique challenges and is a major design driver in the overall system. Pad abort delivers the maximum dynamic pressure and the lowest altitude of all the recovery scenarios. Pad abort requires a drogue release during first stage and hence the highest main parachute dynamic pressure. At the time-of-writing the pad abort sequence follows the following progression, Figure 3 and Figure 4. After this sequence the pilots are deployed and the main sequence progresses nominally as shown in Figure 2.

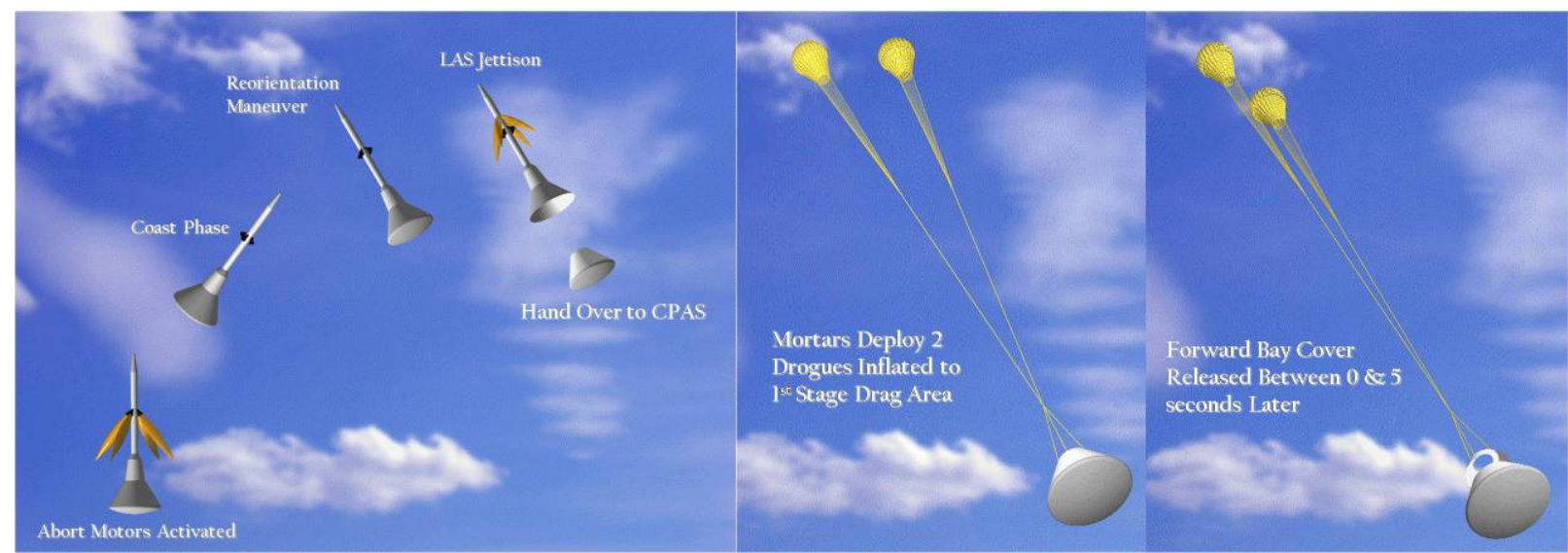

Figure 3. Pad Abort Sequence (Airborne Systems)

\section{Far Field Re-contact}

It is imperative that the jettisoned FBC does not re-contact the descending main cluster. The team decided that augmenting the drag of the FBC system to match the ballistic coefficient of the descending capsule would guarantee that re-contact would be obviated. The approach adopted by the CPAS team was to augment the drag of the system with an additional parachute cluster on the jettisoned FBC. An auxiliary system was designed to deploy following FBC release to increase the drag of the FBC system. The proposed system is extremely lightweight, due to the single digit dynamic pressure deployment conditions. It is deployed by a lightweight drogue gun system. The auxiliary system is shown in Figure 4. 


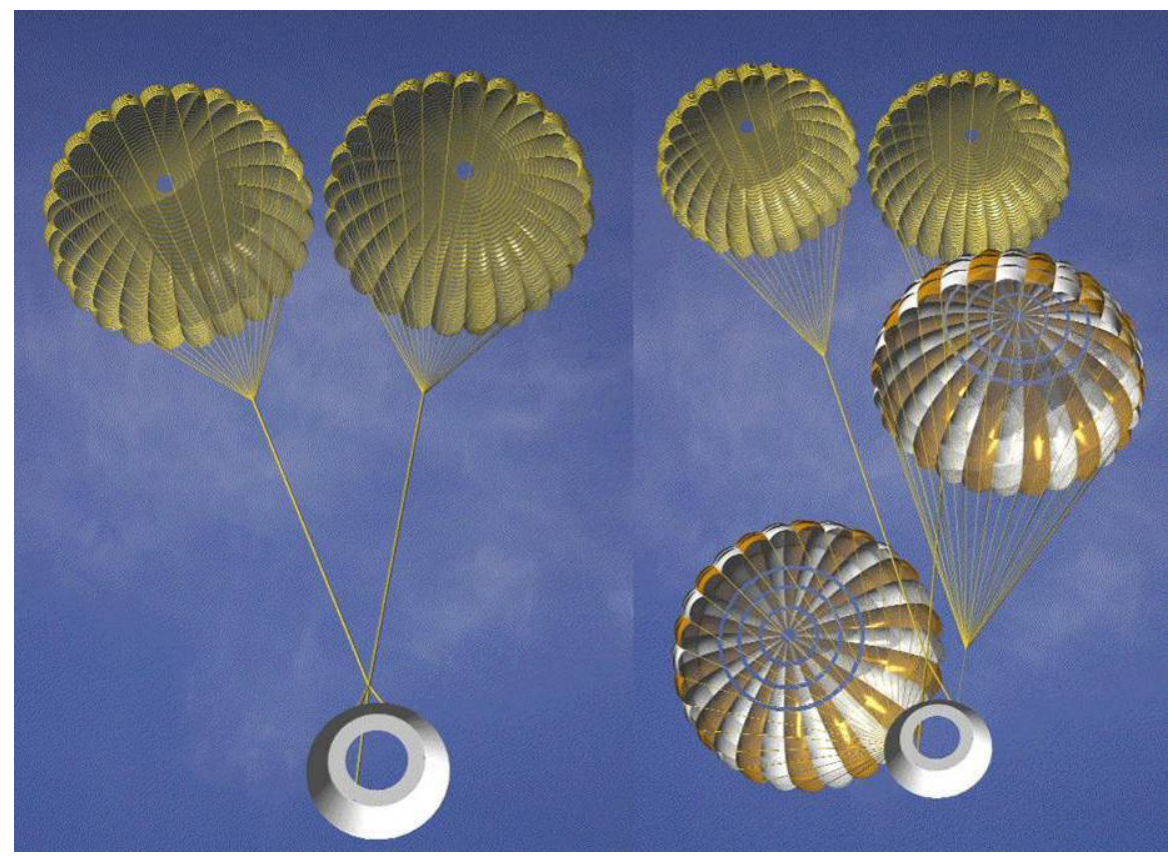

Figure 4. FBC with Auxiliary Parachutes Deployed (Airborne Systems)

The FBC separates and the two auxiliary parachutes deploy to ensure far-field re-contact is eliminated. A single auxiliary parachute is capable of preventing re-contact.

\section{E. System Definition}

The Generation I testing provided the team with sufficient information on the performance of the system to establish the architecture of the flight design unit. Significant attributes are:

- The $23 \mathrm{ft}$ VPCR Drogues will satisfy the requirements of the FDU loads management despite the increase in capsule weight, due to the compensation of the increased capsule drag.

- The 116ft Ringsail main parachutes will satisfy the loads management and terminal velocity requirements of the FDU. The increase in capsule weight was compensated by the increased density at touchdown.

\section{Generation I Testing}

The testing started at a component level to validate single parachute design assumptions. Once the performance of the single parachutes were well understood, clusters of parachute were tested, and finally full system tests were conducted to validate the system performance.

\section{F. Pilots}

Drop tests to develop the pilot parachute were completed using a small drop test vehicle (DTV). During these tests, the DTV was released at altitudes around 10,000 ft MSL. A programmer parachute was used to establish the desired test airspeed and following release, the programmer deployed the pilot parachute, which was the test article. Following the planned sequence of pilot parachute flight, a Saver parachute was deployed to land the DTV and protect onboard instrumentation.

- Instrumentation included:

- Acceleration Data

- Air Data from a sacrificial Pitot probe

- Strain Links

- Onboard Video

- Differential GPS

- Instrumented Range Data 
Four pilot flight tests were completed at US Army Yuma Proving Ground (YPG) and China Lake Naval Weapons Station. Release weight of the DTV was approximately $550 \mathrm{lbs}$ for these tests. Figure 5 provides views of the DTV rigged and ready for release and a view of the pilot parachute in flight.

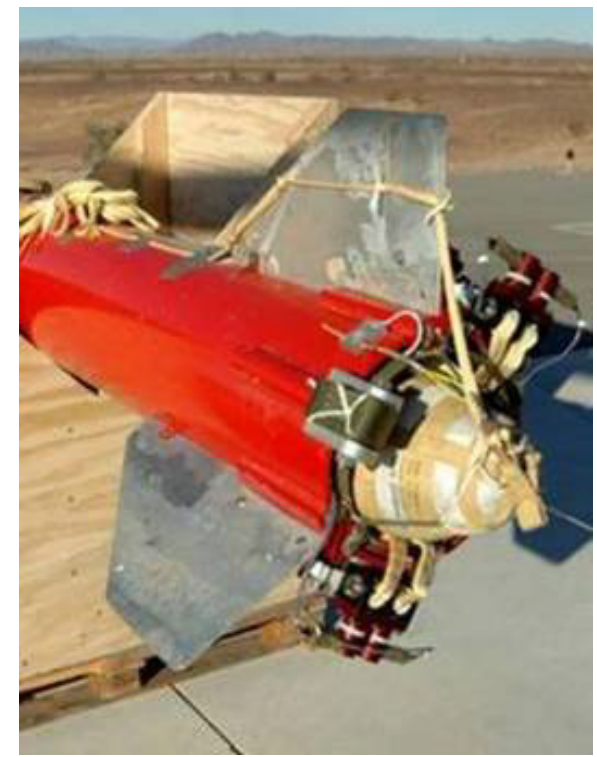

Figure 5. Pilot Parachute Testing (NASA)

\section{G. Drogues}

Three Drogue Development Tests (DDT) were conducted to characterize a single drogue parachute (Figure 6). A Medium Drop Test Vehicle (M-DTV) of approximately 7,000 lbs was used for these tests. This weight is slightly less than half of the Orion capsule. This adjustment was required due to the drag associated with the Orion capsule compared with the relatively low drag DTV.

Single drogue test objectives included:

- Reefing schedule refinement

- Inflation characterization

- Drag area performance

- Parachute structural demonstration

- Parachute stability characterization

Instrumentation was similar to that used on the pilot tests, listed above. The DTV was delivered both with military helicopter and with a Cradle/Monorail System (CMS) from Fox Parachute Systems. The CMS allowed DTV delivery from military cargo aircraft using standard Low Velocity Air Drop (LVAD) techniques. Following extraction, the CMS releases the DTV which begins the test sequence. This technique provides greater range of possible tests due to the higher altitude release, when compared to drops from a helicopter.

On two of the three Drogue tests, a CPAS Main parachute was used as the Saver parachute for the DTV. This provided the opportunity for additional test data at no additional cost. 


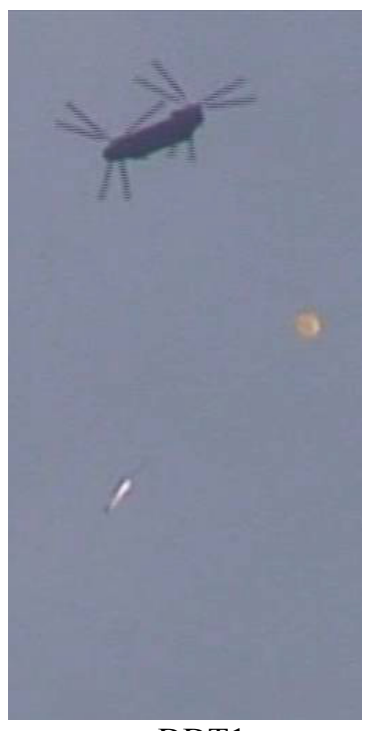

DDT1

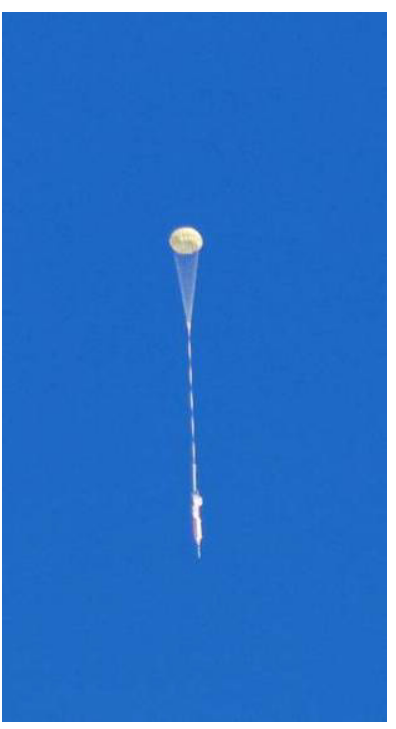

DDT2

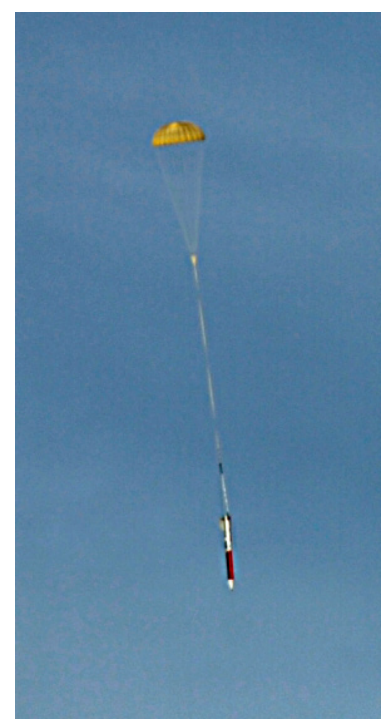

DDT3

Figure 6. Drogue Drop Tests (NASA)

\section{H. Mortar Tests}

Development tests for both drogue and pilot parachute deployment mortars were completed by General Dynamics Ordinance and Tactical Systems (GD-OTS). Laboratory testing included closed bomb tests. Once the propellant load was set, deployment tests with a simulated parachute pack were conducted. Finally, static firings with a representative parachute pack were completed. Success criteria for these tests included an assessment that the parachute skirt region has left the deployment bag. The mortar shots were conducted in a near vertical orientation as the effects of gravity and lack of aerodynamic forces provides a level of conservatism.

Figure 7 shows that the entire parachute was stripped from the parachute pack. Note the compression of the parachute pack as it exits the mortar tube. These parachute mortars were subsequently used for the cluster parachute tests described below. An additional ship set will be flown in the Pad Abort 1 test at White Sands. A set of mortars are currently completing environmental testing to further establish confidence in the design for the Pad Abort 1 mission.
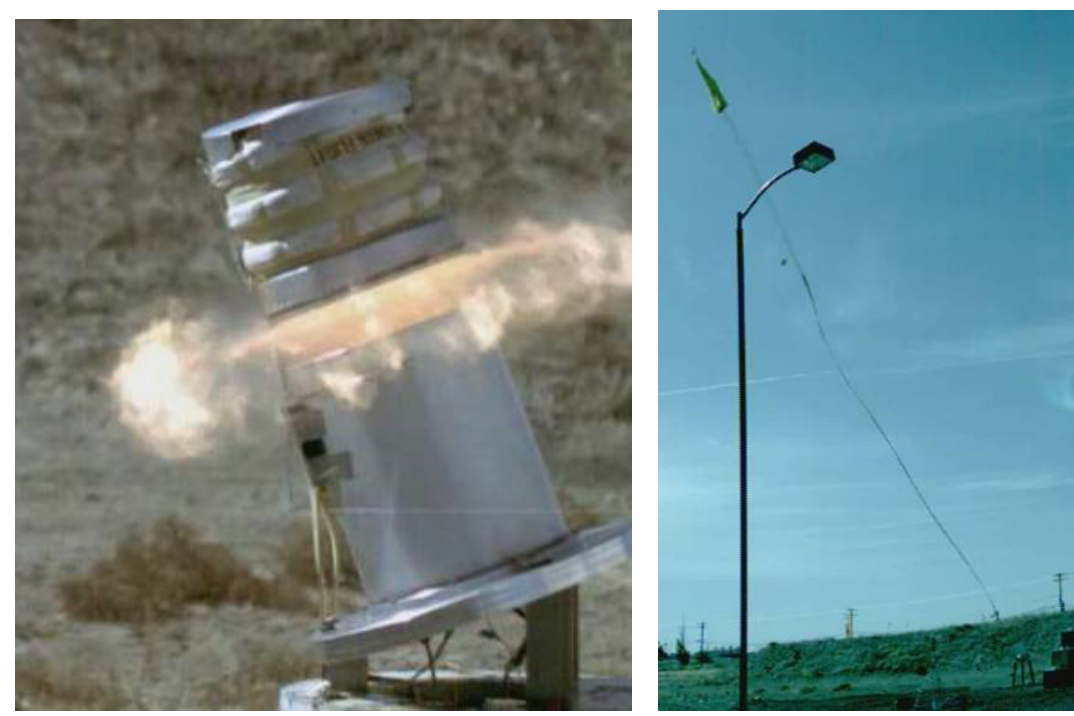

Figure 7. Drogue Mortar During Testing (Airborne Systems) 


\section{Twist Testing}

One of the unique requirements for CPAS is the requirement to limit the torque necessary for the Spacecraft Reaction Control System (RCS) to yaw the spacecraft at landing. This allows a landing loads reduction for the crew due to proper alignment with the ground (water) relative velocity vector.

A series of ground tests were conducted to establish the torque required to twist the spacecraft and to validate a torque reduction device installed in the harness legs below the main confluence fitting.

The test technique involved a weight tub to provide a mass similar to the spacecraft. Three cranes held the ends of parachute riser simulators; one of three cranes is visible in Figure 8. A couple of spread angles between the risers were tested to bound the range expected in flight. A simple lever arm and fish scale was used to rotate the load and measure the torque required. This process was repeated with a metal keeper ring installed, which demonstrated the order of magnitude torque reduction from the keeper.

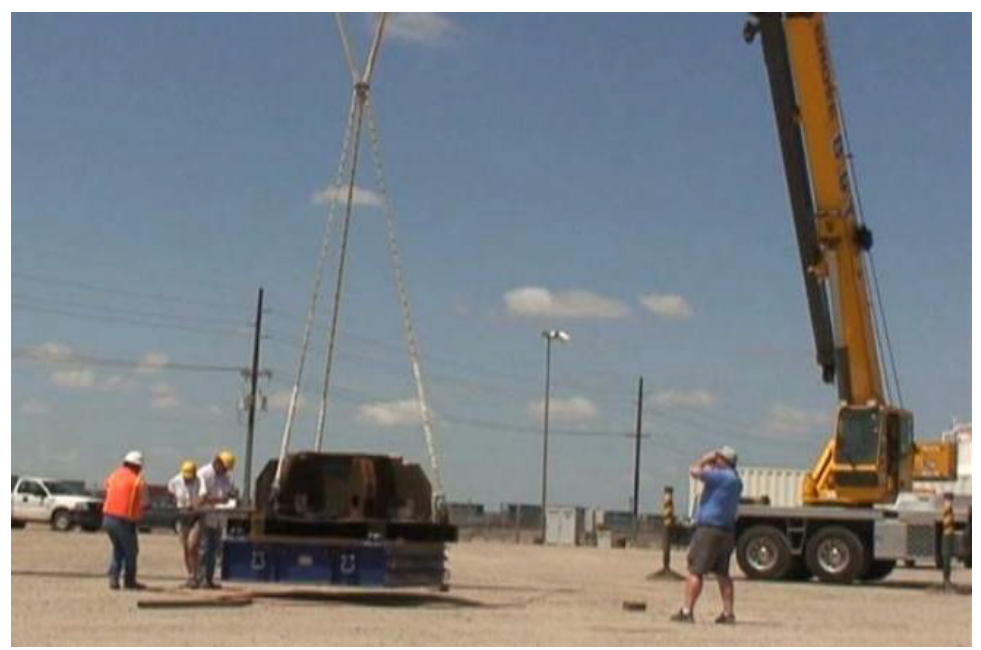

Figure 8. Harness Torque Testing (NASA)

\section{J. Mains}

Main parachute testing began with packing trials and bench deployment tests. Packing trials quickly established the procedures for packing and processing of the large main ringsails into their rather complicated deployment bags. Bench deployments measured required deployment forces for comparison to available pilot parachute forces at all flight conditions. Video and visual inspection confirmed that the parachute deployed in an orderly fashion and that the deployment bag was properly controlling the deployment process. Figure 9 provides some photos of one such bench deployment test. Features of the test include a rolling trolley to reduce friction between parachute pack and pull direction. Not shown are the load cell and data recorder, near the deployment bag handles, and the pulling device (the plant forklift).
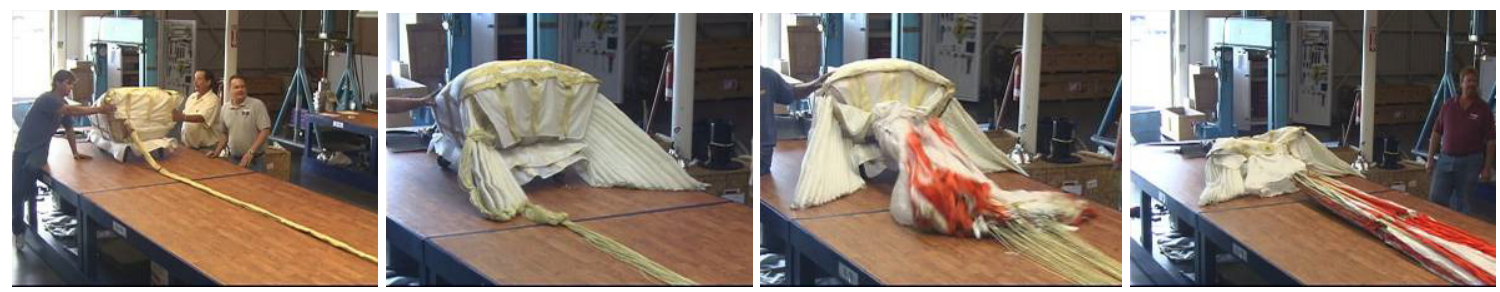

Figure 9. Bench Deployment of a Main Parachute (Airborne Systems)

\section{K. Single Parachute Tests}

Three single main parachute tests were conducted to further advance the main parachute design (Figure 10). Two were conducted with a weight tub and Type V pallet, with a representation of $1 / 6$ of the Orion Forward Bay to stow the parachute. The third used the same M-DTV used in the Drogue flight tests. Test objectives included:

- Main Parachute deployment by Pilot Parachute. All of the tests sequenced through the pilot parachute stage during the test.

- Main Parachute reefing schedule

- Main Parachute inflation characteristics 
The weight tub test design was intended to make full use of the LVAD technique for military aircraft. After the system had left the aircraft in the standard LVAD technique, test sequencing began. This approach provides the easiest path to approval at most US Government Test Facilities. Following aircraft exit, the flight sequence can be modified without formal USAF review.

For the M-DTV test, the CMS system used for the Drogue tests was once more employed. Therefore, standard USAF LVAD procedures were used. This allows a significant reduction in paperwork, and greatly expands the aircraft available to complete the tests. The latter can be very significant in war time.

Following aircraft exit the review cycle is much reduced. At this point, the flight tests deployed parachutes to provide sequence control of the load and the test parachute.

The test loads included the following features:

- Type V Pallet and Load Tub to reach the required weight $(5,000-6,000 \mathrm{lbs})$

- Attachment hardware to support the flight test

- Instrumentation and sequence control

The three MDT tests completed the objectives discussed above. Some level of proof loading was attempted, but at this point in time, rigorous proof tests of the main canopy (ringing it out), are in the future. This is consistent with the current (pre-PDR) stage of the program.

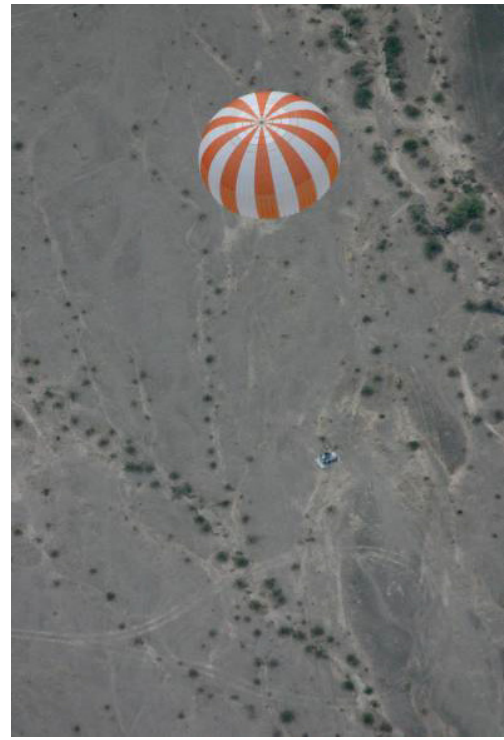

MDT1

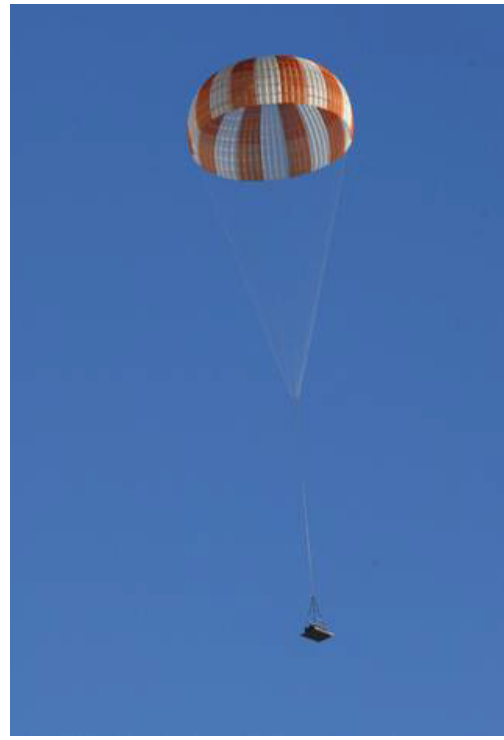

MDT2

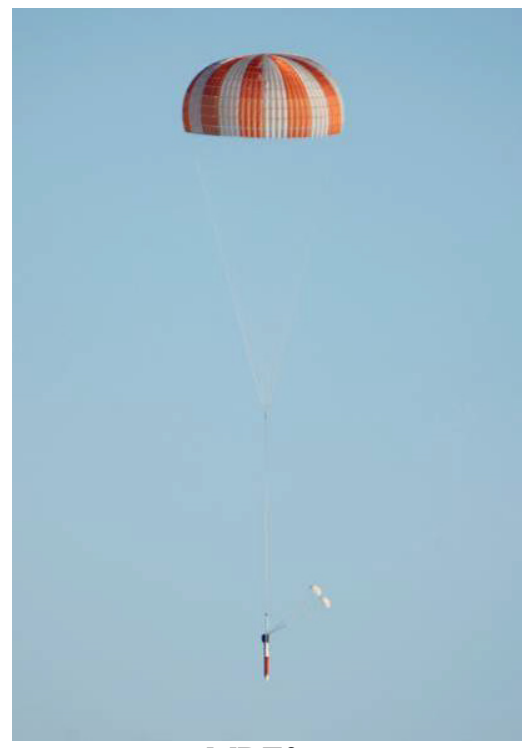

MDT3

Figure 10. Main Drop Tests (NASA)

\section{Cluster Testing}

The Cluster parachute testing did not occur in the planned sequence in the test matrix, thus the test numbers and temporal sequence do not match. This is no real issue, other than an explanation for the reader. The tests are described below, but a brief explanation of the sequence and thinking is appropriate. The testing proceeded as follows and the objectives included:

- CDT-1 - An early look and Cluster deployment and performance

- CDT-3 - Provide an early look at 2 Main parachute performance

- CDT-2 - Exercise parachute system deployment from the Forward Bay region of the spacecraft at the highest fidelity available for our flight test techniques

In the end, CDT-2 was an unfortunate failure due to a number of issues that are discussed in another paper at this conference ${ }^{(1)}$. The failures were totally unrelated to the defined parachute system and are only an issue for delivery of the capsule simulator to the required flight conditions. 


\section{CDT-1}

This test provided the CPAS team with their first look at the pilot parachute deployed scenario. It is similar to the sequence used on Apollo, but it has not been repeated since that program. This test included a geometric representation of the Forward Bay of Orion mounted to a load tub and Type V pallet. This is a very basic simulation of the overall Orion shape, but provides the paperwork relief on delivery from military aircraft. A photo of the final build up is presented in Figure 11.

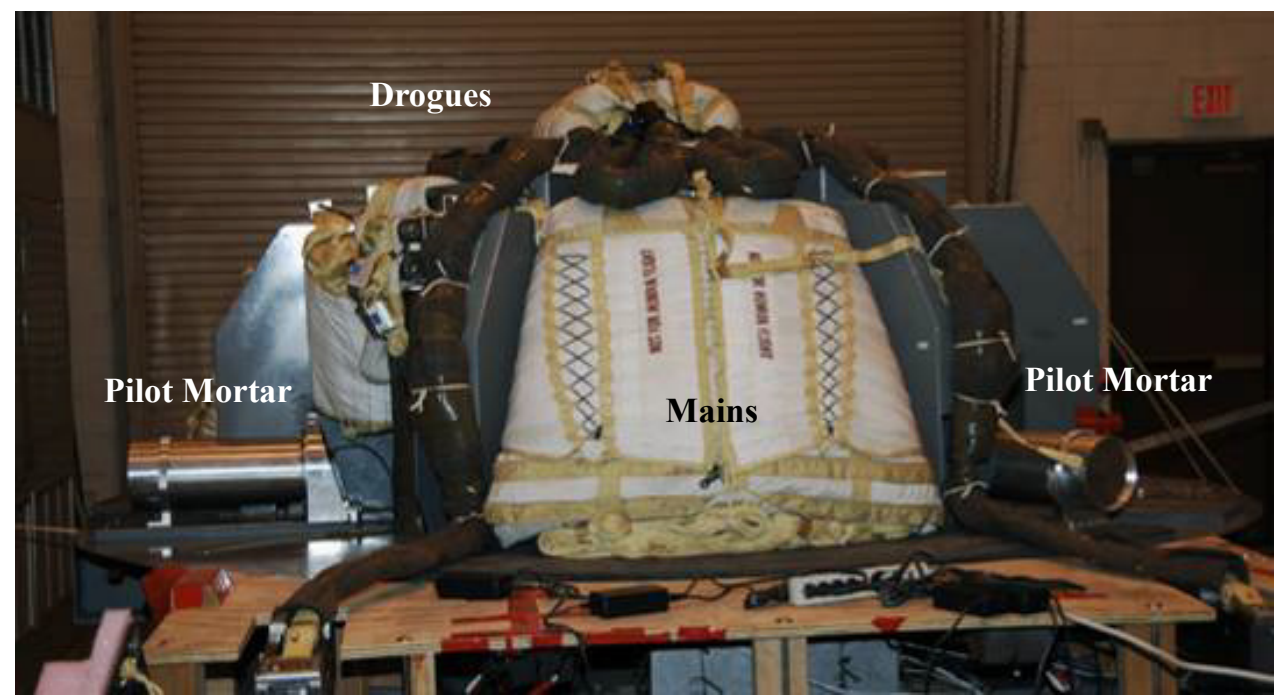

Figure 11. CDT1 Final Buildup (NASA)

The test demonstrated most of the CPAS Generation I architecture and sequencing. The exception was the lack of mortar-deployed drogue parachutes. Instead, the drogues were deployed in a programmer mode by the extraction parachute; this avoided the complications of mortar deployed drogues. For the pilot parachutes, the early baseline configuration was retained; the pilot parachutes were deployed approximately 90 degrees to the velocity vector and performed very well. The deployment sequence is shown in Figure 12. The entire system performed successfully.

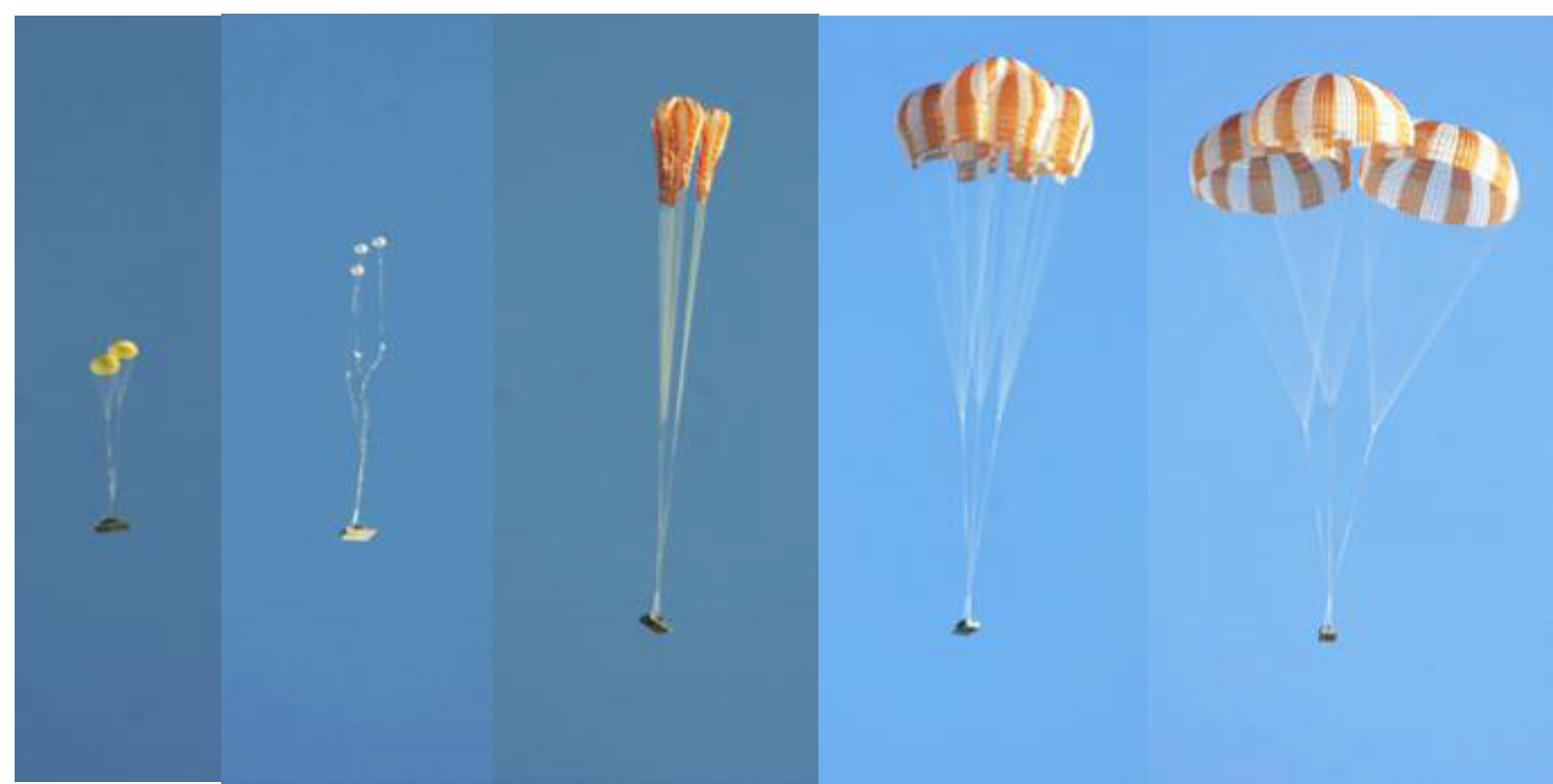

Figure 12. CDT1 Deployment Sequence (NASA)

\section{2. $C D T-3$}

CDT-3 was scheduled to provide data on the performance of a two Main parachute cluster, simulating a oneMain-out condition, which is the fault tolerant baseline configuration for CPAS. The test configuration used a 
standard LVAD delivery technique, a Type V pallet and weight tub for the drop model delivery and transition to programmers and then main parachutes for the drop technique. The test was successful and provided data on the performance of the two main parachute system. The deployment sequence is shown in Figure 13.

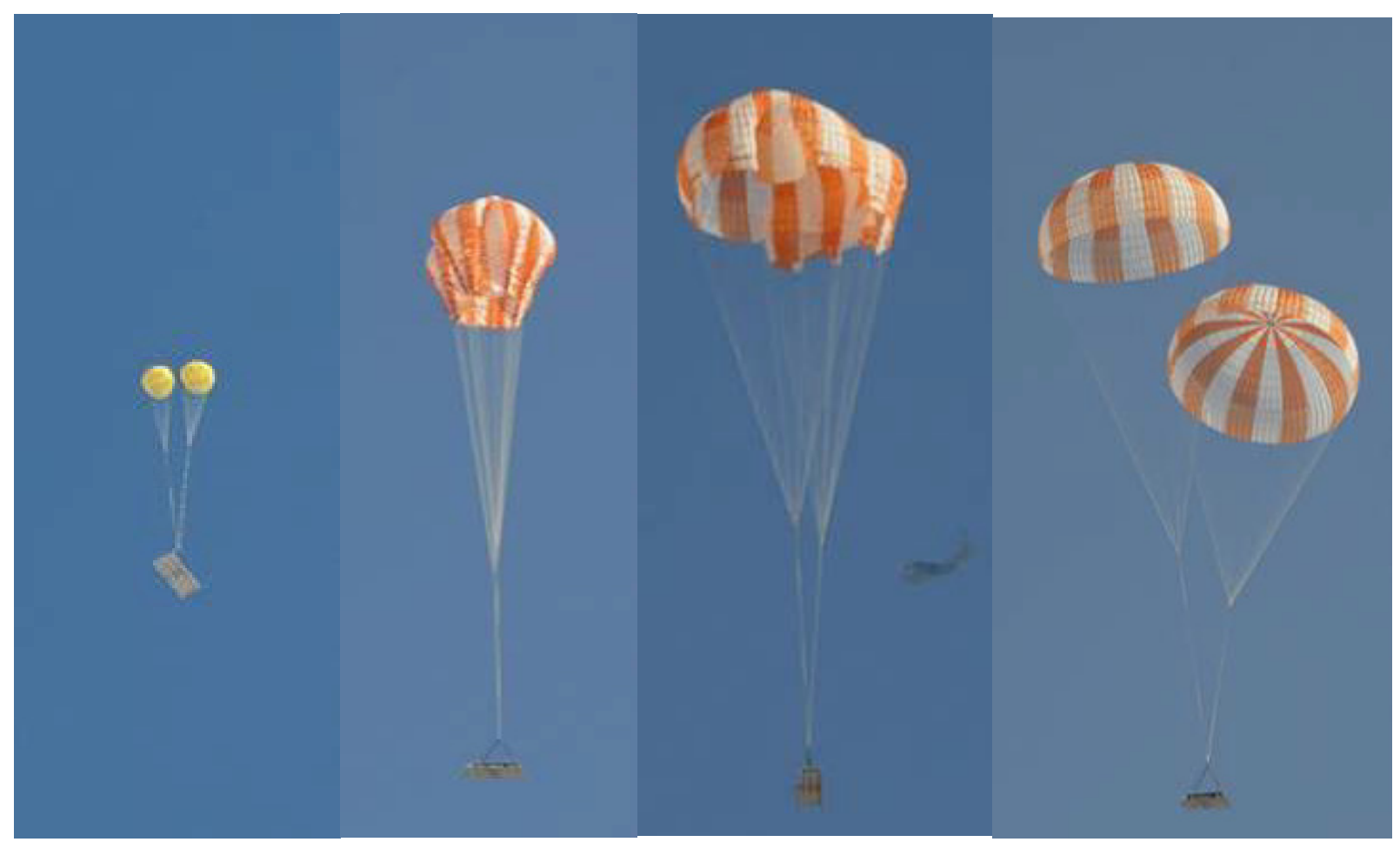

Figure 13. CDT3 Test Sequence (NASA)

\section{Lessons Learned in Test}

The comprehensive development and test effort has been highly successful. The test program has validated the design methodologies and assumptions. The Pilots and Drogues have performed extremely well and have demonstrated good robustness in deployment. The Mains stowage and deployment concept has performed as expected with many deployments demonstrated in tests.

A number of lessons were learned during the Generation I test campaign. Some these are discussed above. A couple deserve special mention, these include:

- The need to develop a detailed Concept of Operations (ConOps) and test articles in parallel to assure that the two work together.

- The importance of detailed simulations to support ConOPs development and sequence definition

- Limitations in the use of freefall only delivery techniques vs. the higher cost of energetic techniques such as rockets.

\section{N. Coming Tests}

The test program for the Engineering Development Unit (EDU) parachutes is only completing definition at the time of this writing. The planned EDU will largely resemble the flight test program presented above. In general the same test techniques are involved; however, additional techniques such as high altitude balloon delivery of a DTV and heat shield simulators are being discussed.

Concurrently, the flight tests for the Orion/Ares program are quickly approaching. Tests relevant to the CPAS program include:

- Orion Pad Abort 1

- Orion Ascent Abort 1-3

- Orion Pad Abort 2

- Ares 1-Y 


\section{Conclusion}

The CPAS program is progressing rapidly toward the definition of a system to support the Orion spacecraft. Our first flight test with the full vehicle is Pad Abort 1, currently scheduled for September 2009. Meanwhile, production of the Flight Development Unit parachutes and subsequent development flight testing is scheduled for October of 2009. We will continue to report on the progress of the CPAS system and expect to be entering the system qualification program before the 2011 Decelerator Conference.

\section{Acknowledgments}

Many NASA and contractor personnel were involved in this comprehensive program and many are credited with the success to date of the program and technology. Particular thanks to the NASA consultant team of Elsa Hennings, Dean Wolf, Roy Fox, and Chuck Lowry for expertise and support in the design and test of this important technology. Appreciation goes to Kelly Hayase and the General Dynamics team responsible for the mortar design, fabrication, and operation. This work would not have been possible without tireless support from the personnel at the Yuma Proving grounds where much of the test program was conducted.

\section{$\underline{\text { References }}$}

1. Taylor, A., Machin, R., Royall, P., Sinclair, R., "Developing the Parachute System for NASA's Orion: An Overview at Inception" 19th AIAA Aerodynamic Decelerator Systems Technology Conference and Seminar, Williamsburg, VA, May 21-24, 2007, AIAA-2007-2577

\section{Koki's paper on CDT2}

3. Olmstead, R. Morris, A., Bledsoe, K., Eglert, M., "Overview of the Crew Exploration Vehicle Parachute Assembly System (CPAS) Generation I Drogue and Pilot Development Test Results", 20th AIAA Aerodynamic Decelerator Systems Technology Conference and Seminar, Seattle, WA, May 4-7, 2009, AIAA-2009-164897

4. Bledsoe, K., Eglert M., Morris, A., Olmstead, R., "Overview of the Crew Exploration Vehicle Parachute Assembly System (CPAS) Generation I Main and Cluster Development Test Results", 20th AIAA Aerodynamic Decelerator Systems Technology Conference and Seminar, Seattle, WA, May 4-7, 2009, AIAA-2009- 64906 